\title{
Our Experience in Pulsatile Tinnitus and a Normal Tympanic Membrane in 66 Patients
}

\author{
Abdelrahman E. M. Ezzatt, ${ }^{1, \odot}$ Mohammed A. Salem ${ }^{1} \quad$ Colin O’Rourke $^{1} \quad$ John E. Fenton ${ }^{1}$ \\ ${ }^{1}$ Department of Ear, Nose, and Throat, University Limerick \\ Hospitals, Limerick, Ireland

\begin{abstract}
Address for correspondence Abdelrahman E. M. Ezzat, MBBCh, MS(ENT), MRCS, DOHNS, MBA, MAcadMEd, FEB (ORL-HNS), FRCS(ORL-HNS), Department of Ear, Nose, and Throat, University Limerick Hospitals, Limerick CW8 1AW, Ireland
\end{abstract} \\ (e-mail: aemei_ibrahim@yahoo.co.uk).
}

\begin{abstract}
Introduction Pulsatile tinnitus (PT) can harbor potentially life-threatening conditions (LTCS), whereby a delay in diagnosis could be disastrous.

Objective The purpose of this study was to ascertain whether associated signs and symptoms at presentation could help identify a subgroup of high-risk patients.

Materials and Methods A total of 66 patients with PT were retrospectively assessed. The diagnoses were classified as group I with an LTC or not in group II.

Results There were 4 patients (6\%) with a final diagnosis of LTC (group I) and 62 patients (94\%) without a final diagnosis of LTC or no diagnosis (group II). The results were not quite statistically significant regarding the trauma and were strongly statisti-

Keywords cally significant regarding headache and the cranial nerve paralysis.

- cranial nerve

Conclusion The combination of PT with any of the three features of occipital head-

- otology

- pulsatile tinnitus ache, cranial nerve palsy, and recent trauma should alert the clinician to potentially serious causes.
\end{abstract}

\section{Introduction}

Tinnitus is classified as either pulsatile or nonpulsatile based on the noted sound. Pulsatile tinnitus (PT) is an audible perception of heartbeat synchronicity, which usually has a vascular etiology. ${ }^{1}$ It is caused by turbulent blood flow generated by increased flow volume or vessel stenosis and may be of arterial or venous origin. ${ }^{2}$ PT occurs in less than $10 \%$ of tinnitus patients ${ }^{3}$ and is usually unilateral. ${ }^{4} \mathrm{PT}$ is therefore a relatively common otologic symptom and both expert consensus and general guidelines recommend that all patients with PT should be investigated. ${ }^{2,3}$ However, despite intensive assessment, no cause is found in up to $30 \%$ of cases and patients often end up on routine waiting lists for relevant imaging. ${ }^{5}$ Life-threatening conditions (LTCs) can present with PT and these may have disastrous consequences, if not managed promptly. Generally, there is a lack of emphasis in the literature on the associated signs and symptoms in patients with PT. The aim of this study was to ascertain whether associated (red flag) features at presentation could help to identify a subgroup of high-risk patients allowing clinicians to request appropriate investigations more expeditiously.

\section{Materials and Methods}

Discretionary ethical approval from the Chairman of the local Ethics committee at the University Hospital Limerick was obtained. A retrospective assessment of a consecutive series of data collected prospectively on all adult patients 18 years or more (66 patients) with PT, who presented to the routine outpatients service of the senior author during a 4-year period (between 2013 and 2017), was performed.

The study was conducted in an academic tertiary care medical center. The investigation was to find different presentation and investigation to elucidate the cause and site for red flag criteria for fast tracking. We divided the patients into the following two groups: Group I, patients with final diagnosis of potentially acute or chronic LTCs; and group II, patients without a final diagnosis of non-LTC. We excluded PT patients with obvious vascular tympanic cavity lesions.

\section{Results}

The study involved 66 patients, 20 males and 45 females (mean age \pm standard deviation [SD] at diagnosis $48.6 \pm$ 
13.1 years and range: $23-86$ years). There were 41 females (69.5\%) and 18 males (30.5\%). There were no sex differences with regard to the symptomatic presentation $(p=0.640)$, as shown in - Table 1. PT was right-sided in 46 cases and left-sided in 20. It was unilateral in 60 cases and bilateral in 6 cases. From the total 66 cases, 4 patients (6\%) were considered to have a final diagnosis of the LTC (group I) and 62 patients (94\%) without a final diagnosis of a LTC or no diagnosis (group II).

\section{Discussion}

The PT can be due to various causes including idiopathic intracranial hypertension (IIH), neoplasm, or vascular disorders, such as hypertension, hyperthyroidism, vascular stenosis, aneurysms, and coronary artery disease. ${ }^{4}$ PT may be the initial manifestation of atherosclerotic carotid artery disease (ACAD) and, therefore, the otolaryngologist may be the first to be consulted for this symptom. ${ }^{6,7}$ Although in our study we have omitted patients with tympanic cavity vascular abnormalities, otoscopy is still the most important examination in PT as it may reveal a retrotympanic lesion such as a high or exposed jugular bulb, aberrant carotid artery, glomus tumor. ${ }^{3}$ PT with a normal tympanic membrane is very common and on reviewing the published data and excluding vascular middle ear masses, the incidence ranges from 75 to $90 \%{ }^{5,7-11}$.

\section{Synopsis of the Findings}

In our cohort of PT with a normal tympanic membrane, $24 \%$ of patients were deemed to be idiopathic. We found LTC in $6 \%$ of patients which was consistent with reports in our discipline with venous anomalies in $1.5 \%$ of patients and traumatic vascular dissection in $1.5 \%$ of patients, followed by multiple sclerosis (MS) in $3 \%$ of patients. The non-LCT etiology involving hypertension, IIH, and vascular stenosis was noted in $69 \%$ of our patients. Our data confirmed that patients presenting with PT, headache, cranial nerve palsy (CNP), and history of trauma possibly harbored a serious condition. We were unable to clarify the speed of inception of PT in the LTC group but the onset of tinnitus in traumatic arteriovenous fistulae (AVF) and carotid artery dissections was usually sudden.

Table 1 Gender distribution according to symptoms

\begin{tabular}{|l|l|l|l|}
\hline Presentation & Male & Female & $\begin{array}{l}\text { Total no. of } \\
\text { patients }\end{array}$ \\
\hline Age $(>60$ y) & 9 & 12 & 21 \\
\hline Headache/facial pain & 2 & 2 & 4 \\
\hline Trauma & 1 & 0 & 1 \\
\hline Hearing loss & 4 & 21 & 25 \\
\hline Vertigo & 2 & 4 & 6 \\
\hline Otalgia & 2 & 3 & 5 \\
\hline Bruit & 1 & 2 & 3 \\
\hline Cranial nerve paralysis & 1 & 2 & 3 \\
\hline $\begin{array}{l}\text { Focal neurological } \\
\text { symptoms }\end{array}$ & 2 & 1 & 3 \\
\hline
\end{tabular}

The acute appearance of PT in association with headache, and/or focal neurological symptoms may therefore be an indicator of a potentially serious underlying condition and requires sooner than routine investigations to elicit or exclude the cause, as in -Table 2. Patient age is also important as studies demonstrate that the age of PT with AVF is between the ages 30 and 40 years.

\section{Strengths of the Study}

All patients attended to and followed-up by the senior author (J.E.F.).

\section{Comparisons with Other Studies}

Idiopathic or essential PT is a term used interchangeably in the literature to describe patients with PT of unclear etiology ${ }^{8}$ that varies greatly among published series from 9 to $55 \%$. $5,7,9-11$

PT in patients with LTC also varies according to the surgical specialty as ear, nose, and throat (ENT) colleagues have estimated that 3 to $5.1 \%$ of their patients had potentially lethal etiology including AVF (2-3.8\%) and dissecting aneurysm (DA) of the internal carotid or posterior communicating arteries (1-1.3\%). ${ }^{5,79}$ In two separate neurosurgical series, 28 to $34 \%$ of cases were reported with hazardous diagnoses involving AVF (26-27\%) and DA of the internal carotid (2-7\%). ${ }^{5,10}$ The incidence of MS causing PT was 3.8\% in one ENT series, which is similar to our findings. ${ }^{10}$

Non-LCT etiology of the PT in series studies conducted by ENT units with a range of 75 to $85 \% 5,7,9$ but more frequent than those managed at neurosurgical departments at 45 to $65 \%$ of cases. ${ }^{10,11}$ This published dichotomy between specialties may be due to the likelihood that several neurosurgical patients may have been referred by ENT specialists but it cannot be confirmed, as the referral pattern is not reported or deducible in these articles.

Thorough history taking and clinical examination are quite obviously the basis for fast tracking of patients with PT with a normal tympanic cavity for appropriate imaging. PT with headaches is the most common combination of clinical symptoms in dural AVF, ${ }^{12}$ while the pain in cases of IIH is usually

Table 2 Comparison between group I (patients with final diagnosis of cause) and group II (patients without final diagnosis of cause)

\begin{tabular}{|l|l|l|l|}
\hline Presentation & No. of patients & Group I & Group II \\
\hline Age $(\geq 60 \mathrm{y})$ & 21 & 0 & 21 \\
\hline Severe headache & 4 & 3 & 1 \\
\hline Trauma & 1 & 1 & 0 \\
\hline Hearing loss & 25 & 4 & 21 \\
\hline Vertigo & 6 & 0 & 6 \\
\hline Otalgia & 5 & 0 & 5 \\
\hline Bruit & 3 & 0 & 3 \\
\hline $\begin{array}{l}\text { Cranial nerve } \\
\text { paralysis }\end{array}$ & 3 & 2 & 1 \\
\hline $\begin{array}{l}\text { Focal neurological } \\
\text { symptoms }\end{array}$ & 3 & 3 & 1 \\
\hline
\end{tabular}


retrobulbar and associated with diplopia in most instances. ${ }^{13}$ Patients presenting with the combination of PT and occipital headache are most concerning for carotid artery dissection $^{14-16}$ or dural AVF. ${ }^{17,18}$ CNP with or without other focal neurological signs in patients complaining of PT may be due to intracranial hemorrhage or progressive MS. ${ }^{19} \mathrm{~A}$ history of trauma is important as tinnitus resulting from head or neck injuries tends to be more severe than that from other causes. ${ }^{12}$ Moreover, fatal causes of posttraumatic dural AVF have been reported,$^{20}$ thus, injury-related PT can be a sign of potentially lethal conditions. ${ }^{21}$ PT is experienced in 16 to $27 \%$ of carotid dissections at the side of the dissection after head trauma. ${ }^{22}$ A traumatic carotid cavernous fistula is seen in $3.8 \%$ of traumatic skull base fractures..$^{18}$ Patient age is also important as studies demonstrate that the age of PT with AV fistula is common between the age of 30 and 45 years, ${ }^{23,24}$ and DA of internal carotid artery has a peak incidence in the fourth decade. ${ }^{25}$ Furthermore, the age of PT with arterial hypertension and vascular stenosis usually develops between the age 45 and 60 years, becoming more prevalent in older individuals. ${ }^{26}$

\section{Clinical Applicability of the Study}

The authors suggest red flag criteria to fast-track investigations in patients with PT and normal tympanic membrane. The combination of PT with any of the three features among occipital headache, cranial nerve palsy, and recent trauma should alert the clinician to potentially serious causes. Speed of onset, young age, or focal neurological symptoms are also important associated features of possible worrisome hidden pathology. Pulsatile tinnitus in combination with vertigo, bruit, or age above 60 years is less likely to be due to priority conditions.

\section{Conclusion}

- PT with a normal otoscopic examination is caused by an LTC inclusive of MS in 5 to $6 \%$ of patients.

- Associated features can help in fast-tracking investigations for patients with a potentially worrisome diagnosis.

- The combination of PT with any of the three features of occipital headache, cranial nerve palsy, and recent trauma should alert the clinician to potentially lethal causes.

- Speed of onset, young age, or focal neurological symptoms are also important associated features of possible serious pathology.

\section{Conflict of Interest}

None declared.

\section{References}

1 Langguth B, Kreuzer PM, Kleinjung T. De Ridder D. Tinnitus: causes and clinical management. Lancet Neurol 2013;12(9):920-930

2 Liyanage SH, Singh A, Savundra P, Kalan A. Pulsatile tinnitus. J Laryngol Otol 2006;120(2):93-97

3 Kircher ML, Standring RT, Leonetti JP. Neuroradiologic assessment of pulsatile tinnitus. Otolaryngol Head Neck Surg 2008;139(2, Suppl):144
4 Wasserman PG, Savargaonkar P. Paragangliomas: classification, pathology, and differential diagnosis. Otolaryngol Clin North Am 2001;34(5):845-862

5 Mattox DE, Hudgins P. Algorithm for evaluation of pulsatile tinnitus. Acta Otolaryngol 2008;128(4):427-431

6 Daneshi A, Hadizadeh H, Mahmoudian S, Sahebjam S, Jalesi A. Pulsatile tinnitus and carotid artery atherosclerosis. Int Tinnitus J 2004;10(2):161-164

7 Sismanis A, Stamm MA, Sobel M. Objective tinnitus in patients with atherosclerotic carotid artery disease. Am J Otol 1994;15(3):404-407

8 Engstrom H, Graf W. On objective tinnitus and its recording. Acta Otolaryngol Suppl 1950;95:127-137

9 Herraiz C, Aparicio JM. Diagnostic clues in pulsatile tinnitus [article in Spanish]. Acta Otorrinolaringol Esp 2007;58(9):426-433

10 Dietz RR, Davis WL, Harnsberger HR, Jacobs JM, Blatter DD. MR imaging and MR angiography in the evaluation of pulsatile tinnitus. AJNR Am J Neuroradiol 1994;15(5):879-889

11 Waldvogel D, Mattle HP, Sturzenegger M, Schroth G. Pulsatile tinnitus-a review of 84 patients. J Neurol 1998;245(3):137-142

12 Sismanis A. Pulsatile tinnitus. Otolaryngol Clin North Am 2003;36(2):389-402

13 Digre KB, Nakamoto BK, Warner JE, Langeberg WJ, Baggaley SK, Katz BJ. A comparison of idiopathic intracranial hypertension with and without papilledema. Headache 2009;49(2):185-193

14 Friedman JA, Meyer FB, Nichols DA, et al. Fatal progression of posttraumatic dural arteriovenous fistulas refractory to multimodal therapy. Case report. J Neurosurg 2001;94(5):831-835

15 Saeed SR, Hinton AE, Ramsden RT, Lye RH. Spontaneous dissection of the intrapetrous internal carotid artery. J Laryngol Otol 1990;104(6):491-493

16 Baumgartner R, Bogousslavsky J. Clinical manifestations of carotid dissection. Front Neurol Neurosci 2005;20:70-76

17 Pons Y, Vérillaud B, Ukkola-Pons E, Sauvaget E, Kania R, Herman P. Pulsatile tinnitus and venous cerebral thrombosis: report of a case and literature review. Rev Laryngol Otol Rhinol (Bord) 2012;133(3):163-164

18 Sigari F, Blair E, Redleaf M. Headache with unilateral pulsatile tinnitus in women can signal dural sinus thrombosis. Ann Otol Rhinol Laryngol 2006;115(9):686-689

19 Vanneste S, Joos K, De Ridder D. Prefrontal cortex based sex differences in tinnitus perception: same tinnitus intensity, same tinnitus distress, different mood. PLoS One 2012;7(2):e31182

20 Redekop GJ. Extracranial carotid and vertebral artery dissection: a review. Can J Neurol Sci 2008;35(2):146-152

21 Kreuzer PM, Landgrebe M, Vielsmeier V. Kleinjung T, De Ridder D, Langguth B. Trauma-associated tinnitus. J Head Trauma Rehabil 2014;29(5):432-442

22 Folmer RL, Griest SE. Chronic tinnitus resulting from head or neck injuries. Laryngoscope 2003;113(5):821-827

23 Chae SW, Kang HJ, Lee HM, Hwang SJ. Tinnitus caused by traumatic posterior auricular artery-internal jugular vein fistula. J Laryngol Otol 2001;115(4):313-315

24 Park SY, Kim SC, Lee KS, Lee KJ. A case of the pulsatile tinnitus due to Post-traumatic arteriovenous fistula involving superficial temporal artery treated with percutaneous embolization. Korean J Otorhinolaryngol-Head Neck Surg 2000;43(6):667-669

25 Schievink WI, Mokri B, O'Fallon WM. Recurrent spontaneous cervical-artery dissection. N Engl J Med 1994;330(6): 393-397

26 Mondelli MFCG, Lopes AC. Relation between arterial hypertension and hearing loss. Int Arch Otorhinolaryngol 2009;13(1):63-68 